

\title{
Epigenetic regulation of the human mucin gene MUC4 in epithelial cancer cell lines involves both DNA methylation and histone modifications mediated by DNA methyltransferases and histone deacetylases
}

\author{
Audrey Vincent, Marie-Paule Ducourouble, Isabelle Van Seuningen
}

\section{To cite this version:}

Audrey Vincent, Marie-Paule Ducourouble, Isabelle Van Seuningen. Epigenetic regulation of the human mucin gene MUC4 in epithelial cancer cell lines involves both DNA methylation and histone modifications mediated by DNA methyltransferases and histone deacetylases. FASEB Journal, 2008, 22 (8), pp.3035-3045. 10.1096/fj.07-103390 . hal-02905794

\author{
HAL Id: hal-02905794 \\ https://hal.science/hal-02905794
}

Submitted on 2 Oct 2020

HAL is a multi-disciplinary open access archive for the deposit and dissemination of scientific research documents, whether they are published or not. The documents may come from teaching and research institutions in France or abroad, or from public or private research centers.
L'archive ouverte pluridisciplinaire HAL, est destinée au dépôt et à la diffusion de documents scientifiques de niveau recherche, publiés ou non, émanant des établissements d'enseignement et de recherche français ou étrangers, des laboratoires publics ou privés. 


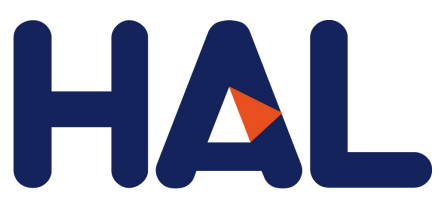

archives-ouvertes

\title{
Epigenetic regulation of the human mucin gene MUC4 in epithelial cancer cell lines involves both DNA methylation and histone modifications mediated by DNA methyltransferases and histone deacetylases
}

\author{
Audrey Vincent, Marie-Paule Ducourouble, Isabelle Seuningen
}

\section{To cite this version:}

Audrey Vincent, Marie-Paule Ducourouble, Isabelle Seuningen. Epigenetic regulation of the human mucin gene MUC4 in epithelial cancer cell lines involves both DNA methylation and histone modifications mediated by DNA methyltransferases and histone deacetylases. FASEB Journal, Federation of American Society of Experimental Biology, 2008, 10.1096/fj.07-103390 . hal-02905794

\section{HAL Id: hal-02905794 \\ https://hal.archives-ouvertes.fr/hal-02905794}

Submitted on 2 Oct 2020

HAL is a multi-disciplinary open access archive for the deposit and dissemination of scientific research documents, whether they are published or not. The documents may come from teaching and research institutions in France or abroad, or from public or private research centers.
L'archive ouverte pluridisciplinaire HAL, est destinée au dépôt et à la diffusion de documents scientifiques de niveau recherche, publiés ou non, émanant des établissements d'enseignement et de recherche français ou étrangers, des laboratoires publics ou privés. 


\title{
The FASEB Journal • Research Communication
}

\section{Epigenetic regulation of the human mucin gene $M U C 4$ in epithelial cancer cell lines involves both DNA methylation and histone modifications mediated by DNA methyltransferases and histone deacetylases}

\author{
Audrey Vincent, Marie-Paule Ducourouble, and Isabelle Van Seuningen ${ }^{1}$ \\ Inserm U837, Jean-Pierre Aubert Research Centre, Place de Verdun, Lille, France
}

ABSTRACT The human gene MUC4 encodes a transmembrane mucin, ligand of ErbB2, that is associated with pancreatic tumor progression. In the normal pancreas, MUC4 is not expressed, whereas activation of its expression is observed in the early steps of pancreatic carcinogenesis. The molecular mechanisms responsible for MUC4 gene activation are however still unknown. The MUC4 5'-flanking region being GC-rich and including two $\mathrm{CpG}$ islands, we hypothesized that epigenetic regulation may be involved and undertook to decipher

AQ: 1 the molecular phenomenons implied. By treating cancer cell lines with 5-aza-2'-deoxycytidine (5-aza) and trichostatin A (TSA), we were able to restore MUC4 expression in a cell-specific manner. We showed by bisulfite-treated genomic DNA sequencing and chromatin immunoprecipitation that methylation of five CpG sites and establishment of a repressive histone code at the $5^{\prime}$-untranslated region were associated with MUC4 silencing and impaired its activation by Sp1. Direct involvement of DNMT3A, DNMT3B, HDAC1, and HDAC3 was demonstrated by RNA interference and chromatin immunoprecipitation. Moreover, inhibition of histone deacetylation by TSA was associated with strong MUC4 repression in high-expressing cells. In conclusion, this work shows for the first time the importance of epigenetics in regulating MUC4 expression and may represent a new strategy to inhibit its expression in epithelial tumors-Vincent, A., Ducourouble, M.-P., Van Seuningen, I. Epigenetic regulation of the human mucin gene MUC4 in epithelial cancer cell lines involves both DNA methylation and histone modifications mediated by DNA methyltransferases and histone deacetylases. FASEB J. 22, 000-000 (2008)

AQ: 2 Key Words: acetylation

DURING TUMOR DEVELOPMENT, aberrant DNA hypermethylation associated with histone deacetylation (1) is a common molecular mechanism that leads to the silencing of numerous genes implicated in cell differentiation, signaling, and DNA repair $(2,3)$. This provides a survival advantage to neoplastic cells and influences drug resistance and clinical outcome after therapy (4). However, gene-specific hypomethylation occurs frequently during carcinogenesis and particularly in colonic and pancreatic cancers and correlates well with increased transcription levels (5). Detection of aberrant promoter methylation (or demethylation) may provide useful tools for early diagnosis and prognosis of cancers, including those of lung (6), pancreas (7), or colon (8). However, although common methylation markers have been clearly established during the past few years (9), identification of panels of complementary biomarkers that are cancer specific is still necessary to establish precise DNA methylation signatures that would be beneficial for patient screening. Hence, studying the methylation status of genes aberrantly expressed in cancers may help in developing these early detection tools (10).

Pancreatic carcinogenesis is a stepwise process characterized by preneoplastic tumors called pancreatic intraepithelial neoplasia (PanIN) with different grades (PanIN1/2A/2B/3) that degenerate into carcinoma (11). Thus, targeting PanIN or genes expressed in PanIN represents a potential therapeutic approach to control pancreatic tumor progression. The human gene MUC4 encodes a transmembrane mucin characterized by a large growth factor-like extracellular domain, ligand of ErbB2, that participates in ErbB2 signaling, cell proliferation, and tumor progression $(12,13)$. In pancreatic cancer, MUC4 has become an important molecular target (14), because it is not expressed in normal pancreas but is increasingly activated during the carcinogenetic sequence as early as PanINs (15). Moreover, its overexpression in pancreatic carcinomas is associated with a bad prognosis. For all these reasons, MUC4 has been recently proposed as a potent diagnostic (16) and prognostic (17) factor as well as a tumor marker (18) in pancreatic cancer. However, despite extensive data at the cellular level, the molecular mechanisms that control MUC4 de novo expression in pancreatic cancer are still unknown.

\footnotetext{
${ }^{1}$ Correspondence: Inserm, U837, Pl. de Verdun, 59045 Lille cedex, France. E-mail: isabelle.vanseuningen@inserm.fr doi: $10.1096 /$ fj.07-103390
} 
The characterization of the 5 '-flanking region of MUC4 in our laboratory showed that it is under the control of two transcriptional units and that both the $5^{\prime}$-untranslated region (5'-UTR) and the proximal promoter are extremely GC-rich (up to $72 \%$ ), whereas the distal promoter is not as GC-rich (up to 65\%) (19). Moreover, the analysis of the genomic DNA sequence indicated the presence of numerous potential methylated cytosine residues as well as two $\mathrm{CpG}$ islands. Considering the biological activities of the mucin MUC4 in tumor progression, its de novo expression in pancreatic cancer or overexpression in early stages of numerous epithelial cancers sustained during the carcinogenetic sequence, and the structure of its $5^{\prime}$-flanking region, we hypothesized that epigenetic mechanisms may be involved and thus undertook to decipher the molecular mechanisms responsible for MUC4 epigenetic regulation in epithelial cancer cells. In this work, we report the identification of key methylated CpG sites and the establishment of a repressive histone code at the $5^{\prime}$-UTR that are associated with the silencing of MUC4 in epithelial cancer cell lines and discuss the possible implications in cancer therapy.

\section{MATERIALS AND METHODS}

\section{Cell lines and cell culture}

The pancreatic (PANC-1, CAPAN-1, and CAPAN-2) and gastric (KATO-III) epithelial cancer cell lines used in this study were cultured as described previously (19-21). The inhibitor of methylation, 5-aza-2'-deoxycytidine (5-aza; $5 \mu \mathrm{M}$, Sigma, Saint-Quentin Fallavier, France), and the inhibitor of histone deacetylase (HDAC), trichostatin A (TSA; $0.3 \mu \mathrm{M}$, Sigma), were added to proliferating cells (PCs) or confluent cells (CCs) for 72 and $24 \mathrm{~h}$, respectively, as described before (22). Cells were then lysed and processed for total RNA extraction or whole cellular extract preparation as described thereafter.

\section{RNA extraction, reverse transcriptase-polymerase chain reaction (RT-PCR), and quantitative real-time PGR (Q-PGR)}

Total RNA was prepared using the QIAamp RNA blood and cell reaction kit (Qiagen, Courtaboeuf, France). Total RNA $(1 \mu \mathrm{g})$ was used to prepare cDNA as described by Vincent $e t$ al. (22). RT-PCR was carried out on cDNA (5 $\mu \mathrm{l})$ using a specific pair of primers for MUC4 (19). The ribosomal RNA $28 \mathrm{~S}$ subunit was used as the internal control (20). Singlestranded oligonucleotides were synthesized by MWG-Biotech (Ebersberg, Germany). PCR products $(10 \mu \mathrm{l})$ were separated on a $1.5 \%$ agarose gel containing ethidium bromide run in $1 \times$ Tris-borate-EDTA buffer. Multiplex Q-PCR was performed in triplicate using the AB 7500 Fast Real-Time PCR System and the Absolute Q-PCR Rox Mix (Applied Biosystems, Courtaboeuf, France). The ribosomal RNA Control Reagent (Applied Biosystems) was used as an internal amplification control. Primer sets for MUC4 were as follows: forward primer: 5'-TCAGCTGAGGCCTTGCCTT-3', reverse primer: 5'-TCAGTCACCTTCCCTTTTCCA-3' , and probe: ${ }^{\text {FAM }} 5^{\prime}$-TAAGGCGCCATTGCTTTTGGGAGA-3' ${ }^{\text {Tamra }}$. Relative transcript levels were calculated using the $2^{-\Delta \Delta C T}$ method. Untreated cells were used as reference samples.

\section{Immunohistochemistry}

PANC-1 cells were passed at $1.5 \times 10^{6}$ cells $/ 75 \mathrm{~cm}^{2}$ flask and grown under standard conditions until they reached confluency, at which time they were treated either for $48 \mathrm{~h}$ with 5 -aza $(5 \mu \mathrm{M})$ or $24 \mathrm{~h}$ with TSA $(0.3 \mu \mathrm{M})$. Cells were then trypsinized, centrifuged, and washed once with $1 \times$ PBS. The cell pellet was fixed in $4 \%(\mathrm{w} / \mathrm{v})$ formaldehyde and embedded in paraffin, and $3 \mu \mathrm{m}$ sections were prepared. Immunohistochemistry, including positive and negative (omitting primary antibody) controls, was performed using an automatic immunostainer (ES; Ventana Medical System, Illkirch, France), as described previously (23). The monoclonal antiMUC4 antibody, which recognizes the tandem repeat region of the apomucin (24), was used at a 1/2000 dilution.

\section{Whole cell extract preparation and Western blotting}

Total cellular extracts from CAPAN-1 and KATO-III cells were prepared using standard procedures as described previously (25). Protein content was measured using the bicinchoninic acid method as described in the manufacturer's instruction manual (Pierce, Perbio Sciences, Brebières, France). MUC4 protein $(>900 \mathrm{kDa})$ and $\beta$-actin $(42 \mathrm{kDa})$ expression were respectively analyzed on $2 \%(\mathrm{w} / \mathrm{v})$ SDS-agarose gels and $10 \%$ SDS-PAGE followed by transfer on nitrocellulose membrane as described in Piessen et al. (25). Prestained protein molecular weight standards were from Life Technologies (CergyPontoise, France). The monoclonal anti-MUC4 antibody was used at a concentration of $1 \mu \mathrm{g} / \mathrm{ml}$. The MUC4/ $\beta$-actin ratio was calculated after scanning protein bands with GelAnalystGelSmart software.

\section{Sodium bisulfite-treated genomic DNA sequencing}

Genomic DNA was extracted from the three cell lines used in this study with the Blood and Cell Culture DNA Maxi Kit (Qiagen). DNA content was quantified at $260 \mathrm{~nm}$ and stored at $+4^{\circ} \mathrm{C}$ until use. Sodium bisulfite conversion was performed using $5 \mu \mathrm{g}$ of genomic DNA from cell lines as described by Ghoshal et al. (26). The promoter sequences of interest were amplified by PCR using AmpliTaq Gold polymerase (Applied Biosystems) as described previously (26). Primer sequences covering the 5'-UTR, the proximal and distal promoters, as well as the two CpG islands were designed using the MethPrimer software (http://www.urogene.org/methprimer/; Table 1). PCR products were cloned into pCR2.1 vector (Invitrogen, Cergy Pontoise, France). At least five positive clones per site were selected for plasmid preparation using QIaprep 8 Miniprep Kit (Qiagen) and sequenced on both strands on an infrared based ABI 3730 XL sequencer (GATC, Konstanz, Germany) using T7 and M13-RP universal primers. The percentage of conversion of non-CpG cytosines was used as an index of overall bisulfite reaction efficiency. Clones with a conversion efficiency of $>97 \%$ were included in the study.

\section{Site-directed mutagenesis, in vitro methylation of $M U C 4$ proximal promoter and $5^{\prime}$-UTR, and cell transfection studies}

QuickChange site directed mutagenesis kit (Stratagene, Amsterdam, The Netherlands) was used to generate site-specific mutations. Oligonucleotides containing the desired mutations are shown in Table 2. Wild-type (WT) and mutated MUC4-pGL3 constructs $(-461 /-1$ region) were digested with SacI-MluI restriction enzymes (Roche Diagnostics, Meylan, France), and the insert was gel-purified as described by 
TABLE 1. Sequences of the pairs of primers used for bisulfite sequencing studies

\begin{tabular}{|c|c|c|c|c|}
\hline Primer pair & Forward primer $\left(5^{\prime}-3^{\prime}\right)$ & Reverse primer $\left(5^{\prime}-3^{\prime}\right)$ & $\begin{array}{l}\text { Primer position } \\
\text { (PCR product size) }\end{array}$ & $\begin{array}{c}\text { Annealing } \\
\text { temperature } \\
\left({ }^{\circ} \mathrm{C}\right)\end{array}$ \\
\hline MUC4 (I) & GGGATAGTGTGTGGTTTAAAAAGTT & CCCTAATCAATAACCCAACATAAAA & $\begin{array}{l}\text { Distal prom. } \\
\quad-3600 /-3380 \\
\quad(221 \mathrm{bp})\end{array}$ & 56 \\
\hline MUC4 (II) & TTTAATTTTGGAAAATGGGTATATTG & AACCAACCAAAATACAAAAAAAATC & $\begin{array}{l}\text { Distal prom. } \\
\quad-2801 /-2595 \\
\quad(207 \mathrm{bp})\end{array}$ & 50 \\
\hline MUC4 (III) & AGGTGTATTTTTATTTTATAGGTGAA & ACAAATAACTAACCTCTTTCCCATAC & $\begin{array}{l}\text { CpG island II } \\
-2400 /-2211 \\
(190 \mathrm{bp})\end{array}$ & 50 \\
\hline MUC4 (IV) & TTTATTTAGAGTTGGAGGGATTGTT & ACTCAAATTTCTACATTCCCAAAC & $\begin{array}{l}\text { Prox. prom. } \\
\quad-1595 /-1370 \\
\quad(226 \mathrm{bp})\end{array}$ & 50 \\
\hline MUC4 (V) & TTATGGGTTTGGGGTTTGTTAT & AAACAAAAACAAAAATACACTATATACC & $\begin{array}{c}\text { CpG island I } \\
-787 /-532 \\
(256 \mathrm{bp})\end{array}$ & 50 \\
\hline MUC4 (VI) & GTTTAGGTTGATGAGAAGTAGAGTAA & CAACAACTACAATATAAAAAACAAAC & $\begin{array}{l}5^{\prime} \mathrm{UTR}-265 /-47 \\
\quad(219 \mathrm{bp})\end{array}$ & 50 \\
\hline
\end{tabular}

PCR product size and primer position refer to the first ATG (19).

Perrais et al. (21) before being methylated (10 $\mu \mathrm{g})$ with $20 \mathrm{U}$ of $\mathrm{mSss}$ (CG) and mHpaII (CCGG) enzymes (New England Biolabs, Ozyme, St-Quentin en Yvelines, France) for $3 \mathrm{~h}$ at $37^{\circ} \mathrm{C}$. The degree of methylation of the fragment was confirmed by testing its resistance to HpaII digestion. The methylated fragments were then ligated into pGL3 basic vector. DNA concentration was measured at $260 \mathrm{~nm}$ before being used in transfection experiments in CAPAN-2 cells as described by Perrais et al. (19). Influence of methylation of WT and mutated MUC4 promoter $(1 \mu \mathrm{g})$ on its transactivation by Sp1 was studied by carrying out cotransfections experiments in the presence of pCMV-Sp1 $(0.5 \mu \mathrm{g})$ expression vector as described in Van Seuningen et al. (27). Samples were tested in triplicate in at least three independent experiments.

\section{Chromatin immunoprecipitation assay}

Cells $\left(1.0 \times 10^{6}\right.$ per antibody) were fixed in $1 \%(\mathrm{v} / \mathrm{v})$ formaldehyde, and chromatin was sonicated and immunoprecipitated as described in Vincent et al. (22) with either $5 \mu \mathrm{g}$ of specific antibodies against histone H3 (antiacetylated lysine, methylated lysine 9, and trimethylated lysine 27; Upstate, Hampshire, UK) or with specific antibodies against chromatin modifier enzymes: DNMT1, DNMT3B, HDAC1, HDAC2, HDAC3 (Abcam, Paris, France), and DNMT3A (Imgenex, CliniSciences, Montrouge, France) or with normal rabbit IgGs (Upstate) at $+4^{\circ} \mathrm{C}$. Immunoprecipitated chromatin (50 ng) was then used as a template for PCR using the following primers: forward primer: 5'-TTTTGTCCTCTTCCCAGGTTC-3' and reverse primer: 5'-TGGCTGCGGCAAAAGTCC3 ', covering the $-153 /+1$ region of MUC4 proximal promoter and 5'-UTR. PCR was performed using AmpliTaq Gold polymerase as described in Piessen et al. (25) with an annealing temperature of $55^{\circ} \mathrm{C}$. PCR products $(20 \mu \mathrm{l})$ were separated on a $2 \%$ agarose gel containing ethidium bromide run in $1 \times$ TBE buffer.

\section{Small interfering RNA (siRNA) assays}

KATO-III cells were seeded the day before transfection in 24-well tissue culture plates at a density of $3 \times 10^{5}$ cells/well in antibiotic free medium. Cells were transfected with either $100 \mathrm{nM}$ of DNMT1, DNMT3A, DNMT3B, HDAC1, HDAC2, or HDAC3 ON-TARGETplus SMARTpool siRNA using $1 \mu \mathrm{l}$ of DharmaFECT4 transfection reagent (Dharmacon, Brebières, France) as described in Piessen et al. (25). Controls included mock-transfected cells and cells transfected with siControl nontargeting siRNA or siControl GAPD siRNA. Total RNA was isolated $48 \mathrm{~h}$ after transfection, and RT-PCR was performed as described above. Primers used for amplification of the internal control GAPDH, and chromatin modifier enzymes are described in Table 3. Samples were tested in triplicate in at least three independent experiments. The $M U C 4 / G A P D H$ ratio was calculated as described above.

TABLE 2. Sequences of the pairs of primers used for site-directed mutagenesis

\begin{tabular}{llc}
\hline \hline Primer pair & \multicolumn{1}{c}{ Sequence $\left(5^{\prime}-3^{\prime}\right)$} & Position \\
\hline Sp1 WT & CCCAGGTTCCCTGGCCCCTTCGGAGAAACGC & $-129 /-122$ \\
Mut\#1 & CCCAGGTTCCCTGGCATCTTCGGAGAAACGC & $-205 /-193$ \\
Sp1 WT & CCTGGTGGGTAGTGGGTGGGGTGAGGAGAGAAAGGG & \\
Mut\#2 & CCTGGTGGGGAGTG_TTGTGTGCTGAGGAGAGAAAGGG & \\
\hline
\end{tabular}

Mutated nucleotides are italicized and underlined. Antisense oligonucleotides were also synthesized and used for site-directed mutagenesis as described in Materials and Methods. 
TABLE 3. Sequences of the pairs of primers used for RT-PCR studies

\begin{tabular}{|c|c|c|c|c|}
\hline Primer pair & Forward primer $\left(5^{\prime}-3^{\prime}\right)$ & Reverse primer $\left(5^{\prime}-3^{\prime}\right)$ & $\begin{array}{c}\text { PCR } \\
\text { product } \\
\text { size (bp) }\end{array}$ & $\begin{array}{c}\text { Annealing } \\
\text { temperature } \\
\left({ }^{\circ} \mathrm{C}\right)\end{array}$ \\
\hline DNMT1 & AGT CGA TGA TAA CAT CCC AG & CAG AAG ATC TCT TTG ATC CG & 891 & 60 \\
\hline DNMT3A & GTT CTC CCT GCC AAA AAG G & TTT TAT TTG CTC CAG GTG GG & 255 & 60 \\
\hline DNMT3B & GTG TCC TTC CAC CCT CTC TT & CCT ACC TTT ATG CCC AAC TC & 467 & 55 \\
\hline HDAC1 & CTG CTT AGT AGC TTT GGA & TAT CTC AAA AAG GAA ACT AGA CT & 236 & 55 \\
\hline HDAC2 & CCC TGA ATT TGA CAG TCT CAC C & CAC AAT AAA ACT TGC CCA GAA AAA C & 173 & 60 \\
\hline HDAC3 & TTC ATA TCC TCC CCA CAC TTG & GAA CCC AGA GAT TTT TGA GGG & 201 & 55 \\
\hline MUC4 & CGC GGT GGT GGA GGC GTT CTT & GAA GAA TCC TGA CAG CCT TCA & 596 & 60 \\
\hline GAPDH & TGAAGGTCGGAGTCAACGGATTTGGT & CATGTGGGCCATGAGGTCCACCAC & 980 & 60 \\
\hline
\end{tabular}

\section{Statistics}

All values in this article are mean $\pm \mathrm{SD}$. When indicated, data were analyzed by Student's $t$ test using GraphPad Prism 4 software (GraphPad, San Diego, CA, USA) with differences $P<0.05$ considered significant.

\section{RESULTS}

Influence of DNA methylation and histone deacetylation on MUC4 expression in epithelial cancer cells

To study the role of methylation and histone acetylation on MUC4 expression, one nonexpressing pancreatic cancer cell line (PANC-1) and one high-expressing pancreatic cancer cell line (CAPAN-1) were treated with either the demethylating agent 5-aza (Fig. 1A) or the HDAC inhibitor TSA (Fig. $1 B$ ). As an intermediate model, the low-expressing gastric cancer cell line (KATO-III) was used. Studies were conducted in PCs and CCs to evaluate epigenetic regulation of MUC4 in both cellular situations.

In nonexpressing pancreatic PANC-1 PCs and CCs, treatment with 5-aza and TSA induced MUC4 expression at the mRNA level (Fig. 1A, B, lanes 2 and 4). Induction of MUC4 protein expression was also observed in a few cells by immunohistochemistry after either 5-aza or TSA treatment (Fig. 1C).

In low-expressing KATO-III PCs, 5-aza and TSA treatments strongly increased MUC4 expression both at the mRNA (4.07- and 3.03-fold increase by Q-PCR, respectively, Fig. $1 A, B$, lane 2 ) and protein (Fig. 1D) levels. In KATO-III CCs, DNA demethylation with 5-aza still induced a 3-fold activation (Q-PCR) of MUC4 mRNA expression and inhibition of histone deacetylation with TSA induced a 2.39-fold activation (Fig. $1 A, B$, lane 4 and Q-PCR).
A
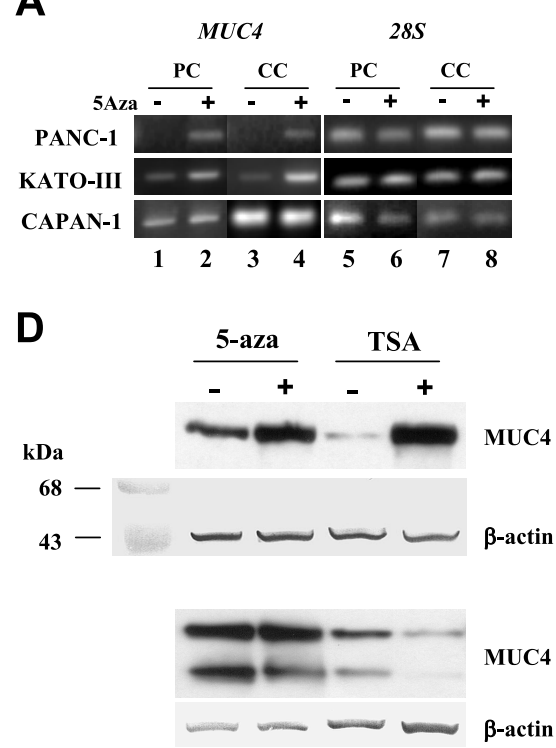

B

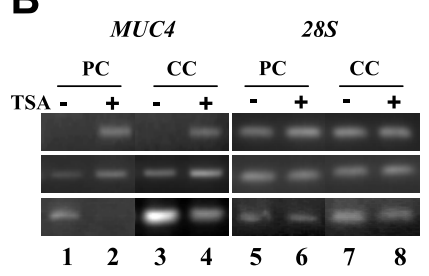

C

PANC-1 (CC)

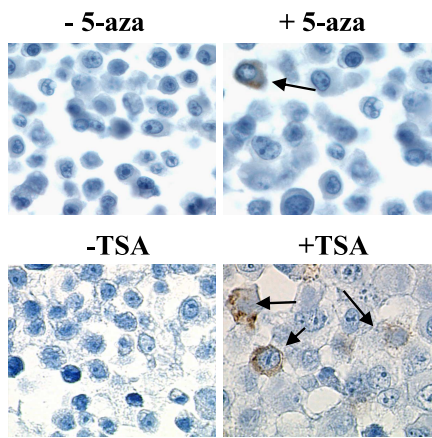

KATO-III (PC) Figure 1. Epigenetic regulation of MUC4 in epithelial cancer cell lines. $A, B)$ RT-PCR was performed as described in Materials and Methods. The expected sizes for PCR products of MUC4 (lanes 1 to 4 ) and 28 S (lanes 5 to $8)$ are 596 and $231 \mathrm{bp}$, respectively. PCR products $(10 \mu \mathrm{l}$ and $5 \mu \mathrm{l})$ were separated on a $1.5 \%$ agarose gel containing ethidium bromide. Untreated $(A:-$, lanes $1,3,5$, and 7 ) or treated $(+$, lanes $2,4,6$, and 8$)$ cells with 5 -aza $(5 \mu \mathrm{M}, 72 \mathrm{~h})$ or TSA $(B: 0.3 \mu \mathrm{M}, 24 \mathrm{~h})$. C) MUC4

immunohistochemical detection in untreated (left panel) and 5-aza- or TSA-treated (right panel) PANC-1 cells was performed as described in Materials and Methods. View $\times 400 . D)$ Influence of 5-aza and TSA treatment on MUC4 apomucin expression in KATO-III PCs and CAPAN-1 CCs. Untreated $(-)$ and 5-aza- or TSA-treated cells $(+)$. Total cellular extracts were prepared as described in Materials and Methods; $20 \mu \mathrm{g}$ of proteins was loaded on a $\%$ (w/v) SDS-agarose gel (MUC4) or 10\% SDS-PAGE $(\beta$-actin) before being transferred onto nitrocellulose membrane and processed for MUC4 and $\beta$-actin immunohistochemical detection. MUC4/ $\beta$-actin ratios are indicated, ratio corresponding to untreated cells was arbitrarily set to 1 . 
In high-expressing pancreatic CAPAN-1 PCs and CCs, 5-aza treatment did not affect MUC4 mRNA level (Fig. $1 A$ and as determined by Q-PCR), whereas TSA treatment induced a strong inhibition of MUC4 mRNA expression (3.22- and 1.87-fold decrease, respectively, Fig. $1 B$, lanes 2 and 4 and Q-PCR) correlated to a strong decrease of the apomucin level in the cells (Fig. 1D).

\section{Mapping of methylated CpG sites within MUC4 promoters and $5^{\prime}$-UTR}

In silico analysis of MUC4 $5^{\prime}$-flanking region using the MethPrimer software indicated the presence of two CpG islands at $-2370 /-2236$ (CpG island II) and $-738 /-593$ (CpG island I), both located in the proximal promoter (Fig. 2A). The $5^{\prime}$-flanking region has a very high GC content (up to $72 \%$ ) almost exclusively concentrated within the proximal promoter and $5^{\prime}$ UTR. Bisulfite-treated DNA sequencing was used to map methylated cytosines within the distal and proximal promoters and $5^{\prime}$-UTR of MUC4 in the three cell lines studied (Fig. 2A). Primer information is given in Table 1. Our results indicate that the two CpG islands are heavily methylated regardless of the level of MUC4 expression in cells. Most of the CpG sites studied are also heavily methylated in the three cell lines except for cytosines in the $-239 /-73$ region of the proximal promoter and $5^{\prime}$-UTR (Fig. 2A). Five of these CpG sites, all located in the $5^{\prime}$-UTR (at $-81,-93,-102,-113$, and -121) were significantly more methylated in the nonexpressing cell line PANC-1 (92\% methylation) compared with the expressing cell line CAPAN-1 (4\% methylation). As expected, in low-expressing KATO-III cells, these $\mathrm{CpG}$ sites showed an intermediate methylation profile (16\% methylation). A more remote cytosine of the proximal promoter at -1432 was also significantly less methylated in CAPAN-1 cells compared with PANC-1. Thus, the pattern of methylation of these six CpG sites is well correlated to the mRNA level of MUC4 in the cells. Among them, the five CpG sites clustered in the $5^{\prime}$-UTR showed a methylation pattern strictly correlated to MUC4 expression. We thus focused the rest of the work on these five $\mathrm{CpG}$ sites. To identify among these five $\mathrm{CpG}$ sites which ones would be sensitive to 5-aza and thus demethylated after cell treatment with that drug, we submitted nonexpressing PANC-1 CCs to 5-aza treatment and compared their methylation profile to genomic DNA from untreated cells. Our results indicate that DNA demethylation by 5-aza was associated with demethylation (60\%) of cytosines at -81 and -93 (Fig. $2 B$ ). This suggests that activation of MUC4 expression in 5-aza-treated PANC-1 cells is correlated to demethylation of these two $\mathrm{CpG}$ sites.

\section{Study of histone $\mathrm{H3}$ modifications at MUC4 $5^{\prime}$-UTR}

To establish histone H3 status in MUC4 $5^{\prime}$-UTR, ChIP assays were carried out with chromatin from the three cell lines used in this study (Fig. 3). In nonexpressing PANC-1 cells, MUC4 5'-UTR DNA covering the $-153 /+1$ region was associated with deacetylated histone H3 (lane 2) and trimethylated K27H3 (lane 4), whereas K9H3 was not methylated (lane 3). In lowexpressing KATO-III cells, histone H3 was also deacetylated at MUC4 5'-UTR (lane 2), which was enriched in methylated K9H3 (lane 3). In high-expressing CAPAN-1 cells, MUC4 expression was correlated to both acetylation and demethylation of histone H3 (lanes 2-4). Thus, inhibition of MUC4 expression in these three epithelial cancer cell lines is associated with
A

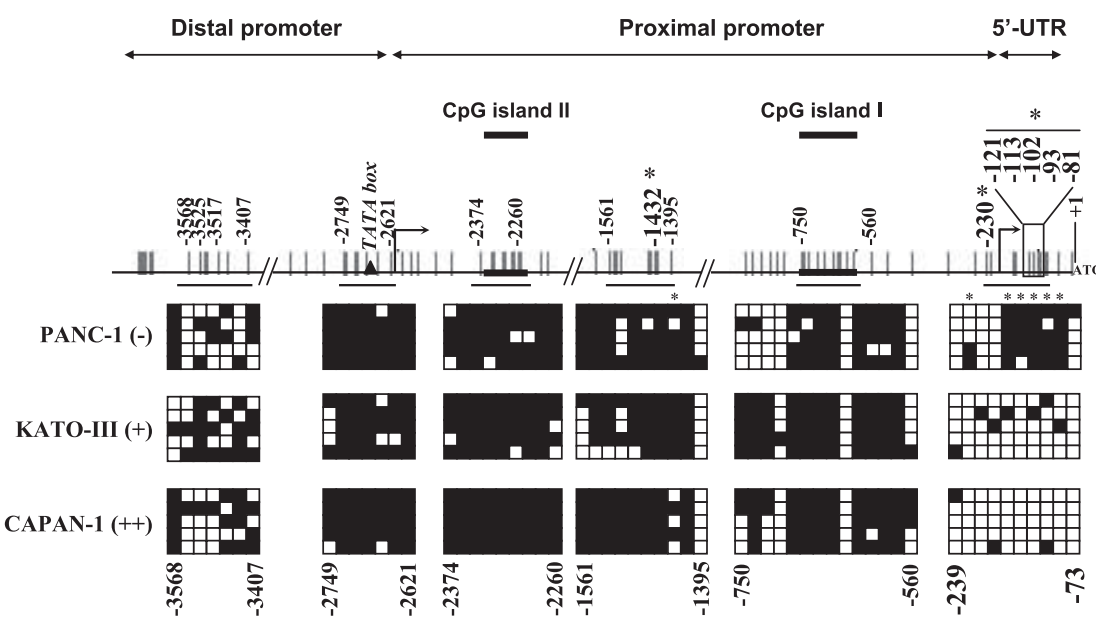



Figure 2. Mapping of methylated cytosines within MUC4 distal and proximal promoters and 5'-UTR by bisulfitetreated DNA sequencing. A) Studies were performed in PANC-1 CC nonexpressing $(-)$, KATO-III CC low-expressing $(+)$, and CAPAN-1 CC $(++)$ MUC4 high-ex-

pressing cells. Numbering refers to the first ATG $(+1)$ of MUC4 gene (19); broken arrows indicate the transcription start sites situated at -199 and -2603 , determining the proximal and the distal promoters of MUC4 (19). Vertical thin bars indicate CpG sites. Horizontal thick bars indicate the positions of the two CpG islands. At least 5 individual clones were analyzed per CpG site (vertical bars) and per cell line. Black squares indicate methylated CpG sites; white squares indicate unmethylated CpG sites. Key CpG methylated sites are topped with a star. B) Mapping of methylated CpG sites of MUC4 5'-UTR in untreated (-, nonexpressing) and 5-aza-treated (+, MUC4-expressing) PANC-1 cells. 


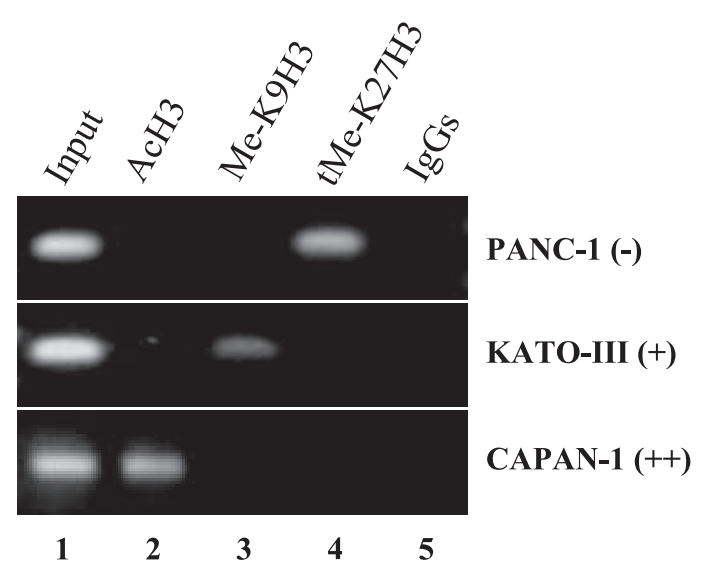

Figure 3. Histone modification status of MUC4 promoter in PANC-1, KATO-III, and CAPAN-1 cell lines. ChIP assays were performed as described in Materials and Methods. Three histone H3 modifications were analyzed: acetylated lysine (AcH3), monomethylated lysine 9 (Me-K9H3), and trimethylated lysine 27 (tMe-K27H3). Input DNA was used as a positive amplification control; IgG indicates ChIP performed using rabbit IgGs as an isotypic antibody control.

establishment of a repressive histone code, including histone $\mathrm{H} 3$ deacetylation and methylation.

DNMT3A, DNMT3B, HDAC1, and HDAC3 chromatin modifier enzymes regulate MUC4 silencing

To identify which DNA methyltransferases (DNMT1, DNMT3A, and DNMT3B) and class I HDACs (HDAC1, HDAC2, and HDAC3) regulate MUC4 endogenous expression, knockdown assays were performed with specific siRNAs in the KATO-III cell line (Fig. 4A). DNMT1 and HDAC1 knockdown led to a 1.8- and 2.9-fold increase of MUC4 expression in KATO-III cells (Fig. $4 B$ ). Knocking down of DNMT3A, DNMT3B, HDAC2, and HDAC3 also led to an increase of MUC4 mRNA expression that was significant (4.4-fold, $P<0.05$; 4.6-fold, $P<0.05$; 3.7-fold, $P<0.005$; and 4.7fold, $P<0.05$, respectively).

To show whether DNMTs and HDACs may directly modify the methylation profile and chromatin structure at MUC4 5'-UTR, ChIP assays were then carried out with chromatin from the three cell lines used in this study (Fig. 4C). In nonexpressing PANC-1 cells, binding of DNMT3A (lane 4), DNMT3B (lane 5), and HDAC1 (lane 6) to DNA covering the $-153 /+1$ region of MUC4 5'-UTR was observed. In low-expressing KATO-III cells, we found binding of DNMT3B (lane 5) and a strong binding of HDAC3 (lane 8). On the contrary, in high-expressing CAPAN-1 cells, neither DNMTs nor HDACs were found to bind MUC4 $5^{\prime}$-UTR. Thus, DNMT3A, DNMT3B, HDAC1, and HDAC3 are directly involved in MUC4 silencing by binding to its $5^{\prime}$-UTR in a cell-specific manner.

Effect of DNA methylation on MUC4 promoter basal activity and regulation by $\mathrm{Spl}$

Having shown that methylation was involved in MUC4 repression, we undertook to study whether promoter methylation could interfere with MUC4 promoter basal activity and regulation by the transcription factor $\mathrm{Sp} 1$, a known regulator of MUC4 transcription (19). These studies were performed in MUC4-expressing pancreatic CAPAN-2 cell line in which MUC4 transactivation by Spl was previously shown to be the strongest (19). In that part of the $5^{\prime}$-flanking region $(-461 /-1)$, which includes part of the proximal promoter and the $5^{\prime}$ -
A

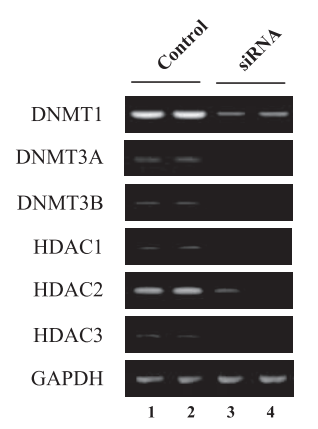

B

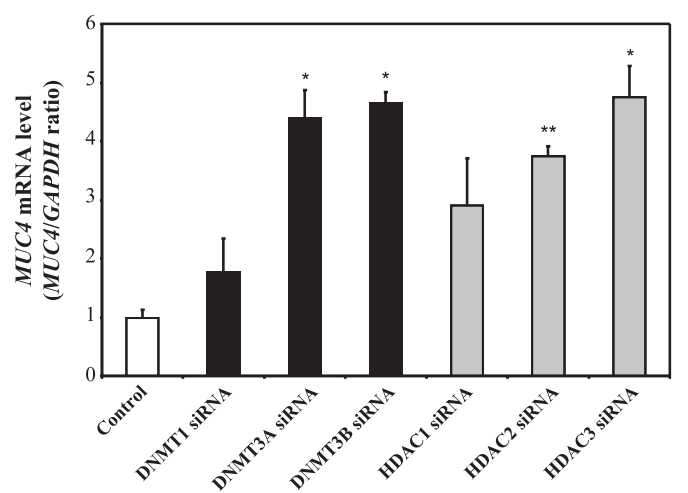

C

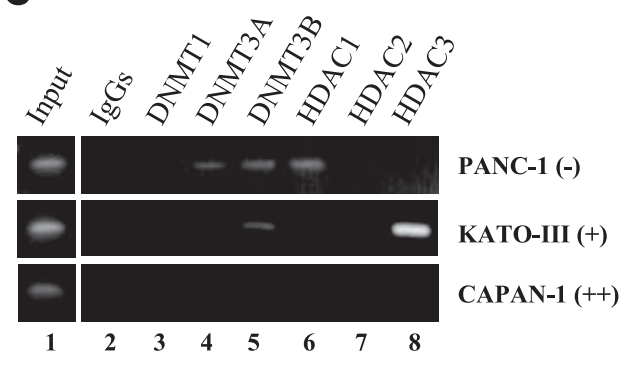

Figure 4. Role of chromatin modifier enzymes (DNMT1, DNMT3A, DNMT3B, HDAC1, HDAC2, and HDAC3) on the endogenous expression of MUC4. A) siRNA knockdown of chromatin modifier enzymes in KATO-III cell line was carried out as described in Materials and Methods. Expression level for each DNMT and HDAC was evaluated by RT-PCR using specific primers (Table 3). Levels of expression of the different genes are shown for cells transfected with nontargeting siRNA (control, lanes 1 and 2) or with specific siRNA (lanes 3 and 4). B) MUC4 and GAPDH mRNA levels were assessed by RT-PCR. PCR products $(10 \mu \mathrm{l} M U C 4,6 \mu \mathrm{l} G A P D H)$ were analyzed on a 1.5\% agarose gel. Diagram shows data expressed as MUC4/GAPDH ratio. Control corresponds to the mean value from mock cells and cells transfected with nontargeting siRNA. Transfections were carried out in triplicate in at least three independent experiments. $* P<0.05 ; * P<0.005$. C) Binding of chromatin modifier enzymes to MUC4 5'-UTR was assessed by ChIP assays using specific antibodies against DNMT1, DNMT3A, DNMT3B, HDAC1, HDAC2, and HDAC3. 
UTR, three Sp1 cis-elements and one Sp1-binding CACCC box have been previously identified (Fig. 5A, black and hatched squares; ref. 19). Among these four cis-elements, those situated at $-129 /-122$ (Sp1) and $-205 /-193$ (CACCC box) do not contain any CpG site (Fig. 5A, hatched squares) and thus are insensitive to DNA methylation.

In vitro methylation of the two other CpG-containing Sp1 sites $(-276 /-271$ and $-166 /-156$, black squares) was carried out with two methylases: $\mathrm{m} S s \mathrm{~s}$, which methylates cytosine residues in $\mathrm{CpG}$ dinucleotides, and $\mathrm{mH}$ HaII, which methylates the second cytosine residue in the CCGG sequence. In the MUC4-461/-1 region, only one mHpaII-sensitive element was found at -346 , next to the four Sp1 binding sites (Fig. $5 A$ ). We then mutated the two CpG-less sites to inactivate them to study the direct effect of methylation of the two ciselements potentially sensitive to methylation at -276 / -271 (Sp1) and -166/-156 (Sp1) (Fig. 5A, black squares) on MUC4 promoter activation by Sp1.

In vitro methylation of the WT MUC4 proximal promoter by $\mathrm{m} S s s \mathrm{I}$ methylase resulted in a total inhibition of its basal activity (Fig. $5 \mathrm{~B}$, white bar) whereas methylation of cytosine at -346 by $\mathrm{mHpaII}$ only led to $40 \%$ decrease of MUC4 promoter activity (Fig. $5 B$, gray bar). Mutation of the cis-element at $-129 /-122$ (Mut\#1) induced a $44 \%$ decrease of MUC4 promoter basal activity, while mutation of the cis-element at
-205/-193 (Mut\#2) induced a 30\% decrease and mutation of both sites (Mut\#3) almost totally abolished MUC4 promoter basal activity ( $78 \%$ decrease) (Fig. $5 B$, black bars). As expected, methylation of the three mutants (Mut\#1, Mut\#2, and Mut\#3) by mSssI resulted in a total inhibition of their basal activity (Fig. $5 B$, white bars). Methylation of the cytosine at -346 by $\mathrm{mHpaII}$ did not further alter transcriptional activity of the three mutants, as the decrease was similar to that observed with the WT construct when compared with respective unmethylated constructs $(30-60 \%$ inhibition; Fig. $5 B$, compare gray bars to black bars).

When cotransfection was performed in the presence of WT MUC4 promoter and an expression vector encoding Sp1, a 4-fold activation was observed (Fig. $5 C$, black bar). Methylation of the MUC4 proximal promoter by $\mathrm{m} S s s \mathrm{I}$ significantly altered its activation by Sp1 (50\% decrease, Fig. 5C, white bar), whereas methylation of the cytosine at -346 by $\mathrm{mH}$ HaII had no effect (Fig. 5C, gray bar). Mutation of the methylation-insensitive Sp1 binding sites, either one site at a time (Mut\#1 and Mut\#2) or both together (Mut\#3), did not further alter MUC4 promoter activation by $\mathrm{Sp} 1$ when unmethylated (Fig. $5 C$, black bars) or when the cytosine at -346 was methylated by $\mathrm{mHpaII}$ (Fig. $5 C$, gray bars). This indicates that 1) the two sites at $-129 /-122$ and $-205 /-193$ do not interfere with MUC4 regulation by


C

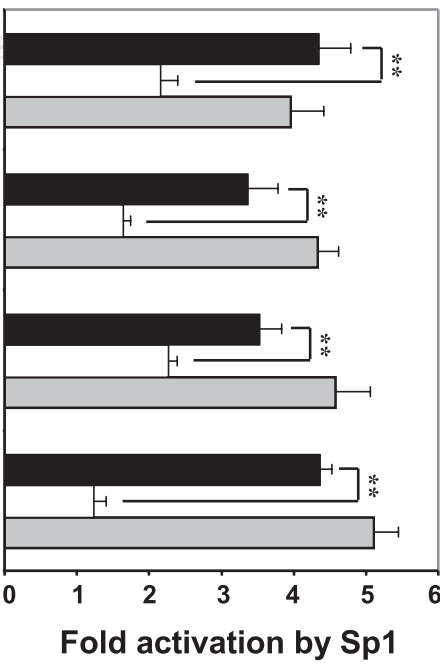

Figure 5. Influence of methylation on MUC4 promoter basal activity and regulation by Sp1. A) Schematic representation of the deletion mutant covering the $-461 /-1$ region of MUC4 proximal promoter and $5^{\prime}-\mathrm{UTR}$. Numbering refers to the first ATG $(+1)$ of MUC4 gene; broken arrow indicates the transcription start site situated at -199 (19). Black squares indicate CpG-containing Sp1 cis-elements; hatched squares are CpG-less Sp1 binding sites (19). Vertical bars indicate CpG sites. The $\mathrm{m} H p a \mathrm{II}$ sensitive site is indicated $(-346, C C G G) . B$ ) Luciferase diagram showing the effect of MUC4 promoter methylation by mSss (CG) or mHpaII (CCGG) on its activity in pancreatic CAPAN-2 cell line. Unmethylated pGL3-MUC4 (-461/-1) (black bars) and corresponding mSssI- (white bars) or $\mathrm{mHpaII-methylated} \mathrm{(gray} \mathrm{bars)} \mathrm{promoter} \mathrm{constructs.} \mathrm{C)} \mathrm{Study} \mathrm{of} \mathrm{the} \mathrm{effect} \mathrm{of}$ promoter methylation on MUC4 transactivation by Sp1. Results are expressed as relative luciferase activity of the unmethylated pGL3-MUC4 constructs (black bars) or the corresponding methylated promoter construct with either $\mathrm{m} S s s \mathrm{I}$ (white bars) or $\mathrm{mH}$ HaII (gray bars) cotransfected with pCMV4-Sp1 expression vector. Transfections were carried out in triplicate in 3 independent experiments. ${ }^{*} P P<0.005$. 
Sp1, and 2) methylation of the adjacent cytosine at -346 does not alter activation by Sp1 either.

Promoter methylation by $\mathrm{m} S s s \mathrm{I}$ (Fig. $5 C$, white bars) did not further alter MUC4 activation by Sp1 when the binding site at $-129 /-122$ (Mut\#1) or at $-205 /-193$ (Mut\#2) was mutated when compared with the corresponding unmethylated constructs (51 and 35\% decrease, respectively). On the contrary, activation by Sp1 was significantly altered with almost total inhibition when the two CpG-less binding sites were mutated (Mut\#3, 72\% decrease). This indicates that direct methylation of the two CpG-containing Sp1 binding sites at $-276 /-271$ and $-166 /-156$ (Fig. 5A, black squares) dramatically impairs MUC4 activation by Sp1.

\section{DISCUSSION}

In this study, we have investigated the role of epigenetics in the regulation of MUC4 mucin gene expression. Our results show that MUC4 is regulated by DNA demethylation and establishment of a derepressive

AQ: 3 histone code at its $5^{\prime}$-UTR involving DNMT3A, DNMT3B, HDAC1, and HDAC3. Moreover, the use of three cell lines with different levels of MUC4 expression allowed us to propose a model for MUC4 epigenetic regulation in epithelial cells (Fig. 6). We propose that in nonexpressing cells, $5^{\prime}$-UTR methylation and a repressive histone code cooperate to silence MUC4 mucin gene, whereas in low-expressing cells, progressive de-

Non-expressing cell (normal cell)

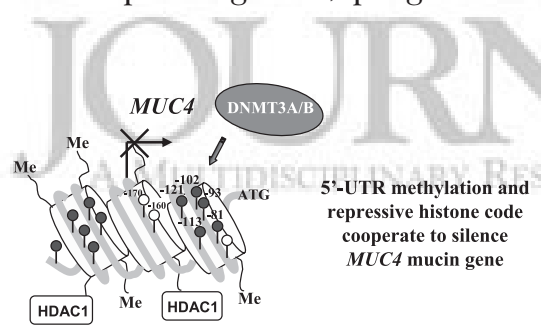

Low-expressing cells (early steps of carcinogenesis)

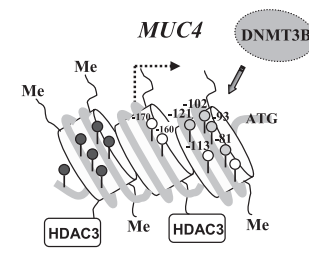
demethylation of the promoter but repressive histone code allows low
expression of MUC4

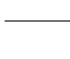

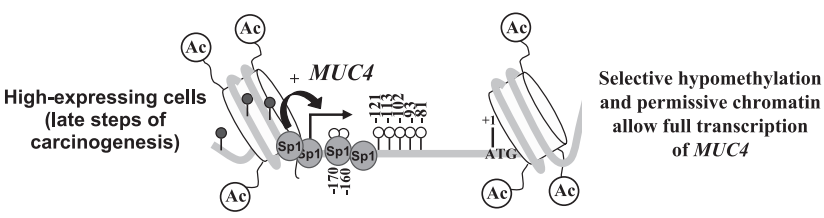

Figure 6. Model for epigenetic regulation of MUC4 expression in epithelial cells based on mechanistic studies in epithelial cancer cell lines expressing different levels of MUC4 gene. Me, methylated cytosine; Ac, acetylated histone. methylation of the promoter but a repressive histone code allows low expression of MUC4; in high-expressing cells, selective hypomethylation and permissive chromatin allow binding of factors such as Sp1 and full transcription of MUC4.

The use of demethylating agent 5-aza and HDAC inhibitor TSA in three cancer cell lines showing different levels of MUC4 expression indicated that DNA methylation and histone deacetylation play an important role in MUC4 silencing. In nonexpressing and low-expressing cells, treatment with the two drugs induced a strong increase in MUC4 expression. This result differs from the paradigm that, in the collaboration between DNA methylation and histone deacetylation in silencing gene expression, DNA methylation is dominant (28), whereas TSA alone is unable to reactivate genes with densely methylated $\mathrm{CpG}$ islands (29). Our results clearly show that both epigenetic mechanisms of DNA methylation and histone deacetylation are involved in the silencing of MUC4, which is consistent with other studies reporting the influence of histone acetylation on the methylation status of genes (30).

Interestingly, we observed that inhibition of histone deacetylation by TSA specifically induced the decrease of both MUC4 gene and apomucin expression in highexpressing cells. We and others $(22,31,32)$ have already shown that HDAC inhibitors are able to inhibit mucin gene expression in cancer cells. In a previous study, Ferguson et al. (33) showed that occupancy levels of the Sp1 transcription factor on the promoter of Hmga2, a gene involved in the control of chromatin structure, decreased significantly after TSA treatment. As Sp1 is an activator of MUC4 transcription (19), the TSA-mediated inhibition of Sp1 DNA binding may explain the decrease in expression observed in this study. However, TSA and other HDAC inhibitors, such as butyrate, have been shown to 1 ) influence cell maturation by repressing secretory markers such as the mucin gene MUC2 (32), 2) induce apoptosis and cell cycle arrest, and 3) enhance the response to chemotherapeutic agents in pancreatic cancer cells (34). As MUC4 is implicated in cell proliferation, invasion, and metastasis in pancreatic cancer (13), the TSA-mediated inhibition of MUC4 we observed next to that of other genes (34) may thus represent the molecular basis for the antitumoral activity of this drug in pancreatic cancer. Moreover, TSA has also been shown to repress expression of the oncogenic ErbB2 (35). Because MUC4 is the ligand of ErbB2, it participates in ErbB2mediated intracellular signaling, its localization, and trafficking $(12,36)$; therefore, the concerted inhibition of both MUC4 and ErbB2 by TSA could also contribute to the antitumor activities of this drug in epithelial cancers implying MUC4-ErbB2 complex formation, a mechanism known to promote tumor proliferation and progression (37). Finally, because MUC4 is often overexpressed in epithelial cancers and is considered as one of the most attractive targets for novel therapeutic strategies $(14,38)$, another application would be to 
target MUC4 high-expressing cells by using pharmacological drugs such as TSA.

The results obtained in pancreatic cancer cell lines (this study) are in accordance with a previous study in which Singh et al. (39) suggested that DNMT and HDAC activity may be involved in the down-regulation of MUC4 in prostate cancer cell lines. However, no mechanisms regarding direct silencing of MUC4 by methylation of CpG sites and/or histone modifications have been studied. It will be interesting in the future to assess whether the mechanisms identified in pancreatic cells are also active in prostate cancer cells.

In this study, we demonstrate that most of the $\mathrm{CpG}$ sites in both promoters and $5^{\prime}$-UTR are highly methylated. Interestingly, the two $\mathrm{CpG}$ islands were hypermethylated in the three cancer cell lines studied regardless of the level of MUC4 expression. Hypermethylation of $\mathrm{CpG}$ islands is a common characteristic of cancer cells (28), and we recently showed that promoters of other mucin genes, encoding secreted mucins MUC5B and MUC6, also have hypermethylated $\mathrm{CpG}$ islands whether these genes are expressed or not in the cancer cells of interest (22).

Among the six differentially methylated CpG sites that were identified in this study, five $\mathrm{CpG}$ sites located in the $5^{\prime}$-UTR at $-81,-93,-102,-113$, and -121 appear as key CpG sites to target in MUC4-expressing tumors because 1) their methylation pattern directly corresponds to the expression level of MUC4 in the cells and 2) in vitro methylation of the DNA region encompassing these CpG sites totally represses MUC4 promoter activity. Moreover, we demonstrated that 5-aza treatment, leading to activation of MUC4 expression was associated with demethylation of two of these CpG sites. To our knowledge, this is the first time that such a mechanism involving direct regulation of MUC4 by methylation of a short region of the $5^{\prime}$-UTR has been reported.

We found differential profile of DNMT binding to MUC4 5'-UTR in nonexpressing cells (DNMT3A and DNMT3B directly bound to MUC4 $5^{\prime}$-UTR in which CpG sites were highly methylated) compared with low-expressing cells in which only DNMT3B was found to bind MUC4 5'-UTR (Fig. 6). This result suggests that binding of DNMT3A is essential for the establishment of the hypermethylated state of MUC4 5'-UTR. Surprisingly, DNMT1, which is known to be responsible for maintaining DNA methylation through cell divisions and which is involved in repression of numerous genes including MUC2 and MUC5B (22), did not bind to MUC4 5'-UTR, and knocking down DNMT1 by siRNA only led to a slight increase of MUC4 mRNA expression, indicating that this enzyme does not play a major role in MUC4 silencing.

It is known that DNA methylation and histone deacetylation are often tightly linked and cooperate to repress gene transcription (28). Our studies of the chromatin status in MUC4 locus and especially histone modifications at the $5^{\prime}$-UTR covering the five CpG sites of interest indicated that complete or partial repression of MUC4 expression is associated with histone $\mathrm{H} 3$ deacetylation and methylation. On the contrary, MUC4 expression is clearly associated with $\mathrm{H} 3$ acetylation and demethylation (Fig. 6).

The role of histone deacetylation was confirmed in our siRNA experiments in which we showed that the three class I HDACs were involved in MUC4 regulation. Interestingly, ChIP assays revealed that control of MUC4 expression involved different HDACs whether it was completely silenced or simply repressed. Indeed, in the nonexpressing cell line, our results showed HDAC1 binding to MUC4 5'-UTR, whereas in the low-expressing cell line, we found binding of HDAC3. It is known that class I HDACs may not be completely redundant and that HDAC3 may have some unique properties (40). In particular, they are associated with different multiprotein silencing complexes, HDAC1 and HDAC2 being associated with Mi2-NuRD and Sin3A complexes (41), while HDAC3 is associated with the nuclear receptor corepressor (N-CoR) complex (40). Here we show that complete or partial silencing of MUC4 involves different mechanisms and thus may probably result in differences in the established histone code. This hypothesis is supported by our ChIP assays showing that MUC4 5'-UTR is associated with methylation of $\mathrm{K} 9 \mathrm{H} 3$ in the nonexpressing cell line, whereas it is associated with trimethylation of $\mathrm{K} 27 \mathrm{H} 3$ in the lowexpressing cell line.

The effect of DNA methylation on promoter activation by $\mathrm{Sp} 1$, a transcription factor that binds GC-rich cis-elements, is rather controversial because some studies $(42,43)$ have shown that Sp1 binding was inhibited by $\mathrm{CpG}$ methylation, while others showed that $\mathrm{Sp} 1$ was able to bind and activate transcription even when the binding site was $\mathrm{CpG}$ methylated (44). We have already shown that activation of $M U C 2$ and $M U C 5 B$ mucin genes by Sp1 was impaired by promoter methylation $(21,22)$. In this work, we found that methylation of two Sp1 cis-elements previously identified in the $-461 /-1$ region (19) altered MUC4 activation by Sp1, whereas methylation of a neighboring $\mathrm{mH} p a \mathrm{II}-\mathrm{sensitive} \mathrm{element}$ had no effect. These findings are different from a previous study in which methylation of adjacent binding sites of $p 21^{\text {Cip } 1}$ promoter but not methylation of the central CpG dinucleotides affected its activation by Sp1 (43). Hence, the effect of methylation on Sp1 transactivating and binding activities is gene specific and may depend both on the strength of the Sp1 interaction with DNA and on the sequence of the Sp1 binding site (consensus or containing mismatch) present in the promoter. Other binding sites for transcription factors involved in MUC4 regulation and that could be influenced by methylation are present in the MUC4 proximal promoter and $5^{\prime}$-UTR. Especially, two functional PEA3 cis-elements (45) could potentially be methylated (46) and consequently alter MUC4 regulation by PEA3. Moreover, it has been suggested that CpG methylation regulates the cell specificity of transforming growth factor (TGF)- $\beta$-responsive genes (47). TGF- $\beta$ was shown to be an activator of MUC4 expression in the 
CAPAN-2 pancreatic cancer cell line (20). The process implies binding of the Smad4 transcription factor to the MUC4 proximal promoter. Hence, methylation of MUC4 5'-UTR could also be a limiting step in its regulation by TGF- $\beta$.

In conclusion, this work shows for the first time the important role of epigenetics in the regulation of MUC4 mucin gene expression and indicates that both DNA methylation and histone modifications coexist and are responsible for MUC4 silencing in epithelial cancer cell lines. MUC4 may thus be considered as a new complementary biomarker, cancer specific, useful to establish methylation signatures. Mechanisms at the DNA level have been deciphered, and we have identified five key CpG sites located in the 5'-UTR, which methylation correlates with MUC4 repression. These CpG sites may provide new biological tools to detect early reactivation of MUC4 expression in cancers and easily screen epithelial tumors overexpressing MUC4. Histone deacetylation, mediated by HDAC1 or HDAC3, also plays an important role in silencing the gene in nonexpressing and low-expressing cell lines. Finally, an important finding was that the HDAC inhibitor TSA was able to strongly repress MUC4 expression in a high-expressing cell line. This result thus provides a new way of repressing MUC4 expression, the ligand of ErbB2 oncogene, by using HDAC inhibitors. It will certainly have important implications at the therapeutic level, because these two proteins form a complex in cancer cells, promote tumor proliferation, and can be inhibited by HDAC inhibitors. Targeting them in tumors in which they are overexpressed with TSA or other HDAC inhibitors appears thus as a very promising therapeutic strategy.

We thank M. Crépin (Laboratoire de Biochimie, Hormonologie, Métabolisme-Nutrition, Oncologie, CHRU-Centre de Biologie-Pathologie, Lille, France) and D. Demeyer and B. Hémon for excellent technical help. We especially thank C. Brand (Inserm U545, Lille, France) for access to Q-PCR technical facility and technical help. A.V. is the recipient of a Conseil Régional Nord-Pas de Calais and the Institut National de la Santé et de la Recherche Médicale Ph.D. fellowship. This work was supported by a grant from l'Association pour la Recherche sur le Cancer (Isabelle Van Seuningen, grant 3872)

\section{REFERENCES}

1. Santos-Rosa, H., and Caldas, C. (2005) Chromatin modifier enzymes, the histone code and cancer. Eur. J. Cancer 41, 2381-2402

2. Esteller, M. (2005) Aberrant DNA methylation as a cancerinducing mechanism. Annu. Rev. Pharmacol. Toxicol. 45, 9-656

3. Jones, P. A., and Baylin, S. B. (2002) The fundamental role of epigenetic events in cancer. Nat. Rev. Genet. 3, 5-428

4. Glasspool, R. M., Teodoridis, J. M., and Brown, R. (2006) Epigenetics as a mechanism driving polygenic clinical drug resistance. Br. J. Cancer 94, 87-1092

5. Wilson, A. S., Power, B. E., and Molloy, P. L. (2007) DNA hypomethylation and human diseases. Biochim. Biophys. Acta $1775,138-162$
6. Belinsky, S. A. (2004) Gene-promoter hypermethylation as a biomarker in lung cancer. Nat. Rev. Cancer 4, 707-717

7. Matsubavashi, H., Canto, M., Sato, N., Klein, A., Abe, T., Yamashita, K., Yeo, C. J., Kalloo, A., Hruban, R., and Goggins, M. (2006) DNA methylation alterations in the pancreatic juice of patients with suspected pancreatic disease. Cancer Res. 66, 1208 1217

8. Grady, W. M., Rajput, A., Lutterbaugh, J. D., and Markowitz, S. D. (2001) Detection of aberrantly methylated hMLH1 promoter DNA in the serum of patients with microsatellite unstable colon cancer. Cancer Res. 61, 900-902

9. Laird, P. W. (2003) The power and the promise of DNA methylation markers. Nat. Rev. Cancer 3, 253-266

10. Shames, D. S., Minna, J. D., and Gazdar, A. F. (2007) Methods for detecting methylation in tumors: from bench to bedside. Cancer Lett. 251, 187-198

11. Hruban, R. H., Wilentz, R. E., and Kern, S. E. (2000) Genetic progression in the pancreatic ducts. Am. J. Pathol. 156, 18211825

12. Carraway, K. L., Ramsauer, V. P., Haq, B., and Carothers Carraway, C. A. (2003) Cell signaling through membrane mucins. Bioessays 25, 66-71

13. Chaturvedi, P., Singh, A. P., Moniaux, N., Senapati, S., Chakraborty, S., Meza, J. L., and Batra, S. K. (2007) MUC4 mucin potentiates pancreatic tumor cell proliferation survival and invasive properties and interferes with its interaction to extracellular matrix proteins. Mol. Cancer Res. 5, 309-320

14. Singh, A. P., Chaturvedi, P., and Batra, S. K. (2007) Emerging roles of MUC4 in cancer: a novel target for diagnosis and therapy. Cancer Res. 67, 433-436

15. Swartz, M. J., Batra, S. K., Varshney, G. C., Hollingsworth, M. A., Yeo, C. J., Cameron, J. L., Wilentz, R. E., Hruban, R. H., and Argani, P. (2002) MUC4 expression increases progressively in pancreatic intraepithelial neoplasia. Am. J. Clin. Pathol. 117, $791-796$

16. Jhala, N., Jhala, D., Vickers, S. M., Eltoum, I., Batra, S. K., Manne, U., Eloubeidi, M., Jones, J. J., and Grizzle, W. E. (2006) Biomarkers in diagnosis of pancreatic carcinoma in fine-needle aspirates. Am. J. Clin. Pathol. 126, 572-579

17. Saitou, M., Goto, M., Horinouchi, M., Tamada, S., Nagata, K. Hamada, T., Osako, M., Takao, S., Batra, S. K., Aikou, T., Imai, K., and Yonezawa, S. (2005) MUC4 expression is a novel prognostic factor in patients with invasive ductal carcinoma of the pancreas. J. Clin. Pathol. 58, 845-852

18. Iacobuzio-Donahue, C. A., Ashfaq, R., Maitra, A., Adsay, N. V., Shen-Ong, G. L., Berg, K., Hollingsworth, M. A., Cameron, J. L., Yeo, C. J., Kern, S. E., Goggins, M., and Hruban, R. H. (2003) Highly expressed genes in pancreatic ductal adenocarcinomas: a comprehensive characterization and comparison of the transcription profiles obtained from three major technologies. Cancer Res. 63, 8614-862

19. Perrais, M., Pigny, P., Ducourouble, M. P., Petitprez, D., Porchet, N., Aubert, J. P., and Van Seuningen, I. (2001) Characterization of human mucin gene MUC4 promoter: importance of growth factors and proinflammatory cytokines for its regulation in pancreatic cancer cells. J. Biol. Chem. 276, 30923-30933

20. Jonckheere, N., Perrais, M., Mariette, C., Batra, S. K., Aubert, J. P., Pigny, P., and Van Seuningen, I. (2004) A role for human MUC4 mucin gene, the ErbB2 ligand, as a target of TGF-beta in pancreatic carcinogenesis. Oncogene 23, 5729-5738

21. Perrais, M., Pigny, P., Buisine, M. P., Porchet, N., Aubert, J. P., and Van Seuningen-Lempire, I. (2001) Aberrant expression of human mucin gene MUC5B in gastric carcinoma and cancer cells. Identification and regulation of a distal promoter. J. Biol. Chem. 276, 15386-15396

22. Vincent, A., Perrais, M., Desseyn, J. L., Aubert, J. P., Pigny, P., and Van Seuningen, I. (2007) Epigenetic regulation (DNA methylation, histone modifications) of the $11 \mathrm{p} 15$ mucin genes (MUC2, MUC5AC,. MUC5B,. MUC6) in epithelial cancer cells. Oncogene 26, 6566-6576

23. Mariette, C., Perrais, M., Leteurtre, E., Jonckheere, N., Hemon, B., Pigny, P., Batra, S. K., Aubert, J. P., Triboulet, J. P., and Van Seuningen, I. (2004) Transcriptional regulation of human mucin MUC4 by bile acids in oesophageal cancer cells is promoter-dependent and involves activation of the phosphatidylinositol 3-kinase signalling pathway. Biochem. J. 377, $701-708$ 
24. Moniaux, N., Varshney, G. C., Chauhan, S. C., Copin, M. C., Jain, M., Wittel, U. A., Andrianifahanana, M., Aubert, J. P., and Batra, S. K. (2004) Generation and characterization of antiMUC4 monoclonal antibodies reactive with normal and cancer cells in humans. J. Histochem. Cytochem. 52, 253-261

25. Piessen, G., Jonckheere, N., Vincent, A., Hemon, B., Ducourouble, M. P., Copin, M. C., Mariette, C., and Van Seuningen, I. (2006) Regulation of the human mucin MUC4 by taurodeoxycholic and taurochenodeoxycholic bile acids in oesophageal cancer cells is mediated by hepatocyte nuclear factor lalpha. Biochem. J. 402, 81-91

26. Ghoshal, K., Majumder, S., Li, Z., Dong, X., and Jacob, S. T. (2000) Suppression of metallothionein gene expression in a rat hepatoma because of promoter-specific DNA methylation. J. Biol. Chem. 275, 539-547

27. Van Seuningen, I., Perrais, M., Pigny, P., Porchet, N., and Aubert, J. P. (2000) Sequence of the 5'-flanking region and promoter activity of the human mucin gene MUC5B in different phenotypes of colon cancer cells. Biochem. J. 348, 675-686

28. Herman, J. G., and Baylin, S. B. (2003) Gene silencing in cancer in association with promoter hypermethylation. N. Engl. J. Med. 349, 2042-2054

29. Cameron, E. E., Bachman, K. E., Myohanen, S., Herman, J. G., and Baylin, S. B. (1999) Synergy of demethylation and histone deacetylase inhibition in the re-expression of genes silenced in cancer. Nat. Genet. 21, 103-107

30. Cervoni, N., and Szyf, M. (2001) Demethylase activity is directed by histone acetylation. J. Biol. Chem. 276, 40778-40787

31. Gaudier, E., Jarry, A., Blottiere, H. M., de Coppet, P., Buisine, M. P., Aubert, J. P., Laboisse, C., Cherbut, C., and Hoebler, C. (2004) Butyrate specifically modulates MUC gene expression in intestinal epithelial goblet cells deprived of glucose. Am. J. Physiol. Gastrointest. Liver Physiol. 287, G1168-G1174

32. Augenlicht, L., Shi, L., Mariadason, J., Laboisse, C., and Velcich, A. (2003) Repression of MUC2 gene expression by butyrate, a physiological regulator of intestinal cell maturation. Oncogene 22, 4983-4992

33. Ferguson, M., Henry, P. A., and Currie, R. A. (2003) Histone deacetylase inhibition is associated with transcriptional repression of the Hmga2 gene. Nucleic Acids Res. 31, 3123-3133

34. Donadelli, M., Costanzo, C., Beghelli, S., Scupoli, M. T., Dandrea, M., Bonora, A., Piacentini, P., Budillon, A., Caraglia, M. Scarpa, A., and Palmieri, M. (2007) Synergistic inhibition of pancreatic adenocarcinoma cell growth by trichostatin A and Gemcitabine. Biochim. Biophys. Acta 1773, 1095-1106

35. Scott, G. K., Marden, C., Xu, F., Kirk, L., and Benz, C. C. (2002) Transcriptional repression of ErbB2 by histone deacetylase inhibitors detected by a genomically integrated ErbB2 promoterreporting cell screen. Mol. Cancer Ther. 1, 385-392
36. Carraway, C. A., and Carraway, K. L. (2007) Sequestration and segregation of receptor kinases in epithelial cells: implications for ErbB2 oncogenesis. Sci. STKE, 381, re3

37. Carraway, K.L. 3rd, Funes, M., Workman, H. C., and Sweeney, C. (2007) Contribution of membrane mucins to tumor progression through modulation of cellular growth signaling pathways. Curr. Top. Dev. Biol. 78, 1-22

38. Singh, M., and Maitra, A. (2007) Precursor lesions of pancreatic cancer: molecular pathology and clinical implications. Pancre atology 7, 9-19

39. Singh, A. P., Chauhan, S. C., Bafna, S., Johansson, S. L., Smith, L. M., Moniaux, N., Lin, M. F., and Batra, S. K. (2006) Aberrant expression of transmembrane mucins, MUC1 and MUC4, in human prostate carcinomas. Prostate 66, 421-429

40. Karagianni, P., and Wong, J. (2007) HDAC3: taking the SMRTN-CoRrect road to repression. Oncogene 26, 5439-5449

41. Sansom, O. J., Maddison, K., and Clarke, A. R. (2007) Mechanisms of disease: methyl-binding domain proteins as potential therapeutic targets in Cancer Nat. Clin. Pract. Oncol. 4, 305-315

42. Clark, S. J., Harrison, J., and Molloy, P. L. (1997) Sp1 binding is inhibited by $(\mathrm{m}) \mathrm{Cp}(\mathrm{m}) \mathrm{CpG}$ methylation. Gene 195, 67-71

43. Zhu, W. G., Srinivasan, K., Dai, Z., Duan, W., Druhan, L. J., Ding, H., Yee, L., Villalona-Calero, M. A., Plass, C., and Otterson, G. A. (2003) Methylation of adjacent CpG sites affects Sp1/Sp3 binding and activity in the p21 (Cip1) promoter. Mol. Cell. Biol. 23, 4056-4065

44. Holler, M., Westin, G., Jiricny, J., and Schaffner, W. (1988) Sp1 transcription factor binds DNA and activates transcription even when the binding site is CpG methylated. Genes Dev. 2, 11271135

45. Gaston, K., and Fried, M. (1995) CpG methylation and the binding of YY1 and ETS proteins to the Surf-1/Surf-2 bidirectional promoter. Gene 157, 257-259

46. Fauquette, V., Perrais, M., Cerulis, S., Jonckheere, N., Ducourouble, M. P., Aubert, J. P., Pigny, P., and Van Seuningen, I. (2005) The antagonistic regulation of human MUC4 and ErbB-2 genes by the Ets protein PEA3 in pancreatic cancer cells: implications for the proliferation/differentiation balance in the cells. Biochem. J. 386, 35-45

Yamane, K., Suzuki, H., Ihn, H., Kato, M., Yoshikawa, H., and Tamaki, K. (2005) Cell type-specific regulation of the TGF-betaresponsive alpha2(I) collagen gene by CpG methylation. J. Cell. Physiol. 202, 822-830
Received for publication December 5, 2007. Accepted for publication April 10, 2008. 


\section{AUTHOR QUERIES}

AUTHOR PLEASE ANSWER ALL QUERIES

1-Please define GC and CpG if possible.

2-Per journal style, key words must not repeat terms that appear in the title. Please add up to 5 additional key words.

3- "DNA demethylation and establishment of a derepressive histone code" correct as edited? Or was "DNA demethylation or methylation and establishment of a derepressive or repressive histone code" meant? 